\title{
The Metabolic and Hormonal Responses to a Mixed Meal in Unrestrained Pancreatectomised Dogs Chronically Treated by Portal or Peripheral Insulin Infusion
}

\author{
Y. Goriya ${ }^{3}$, A. Bahoric ${ }^{1}$, E. B. Marliss ${ }^{2}$, B. Zinman ${ }^{2}$ and A. M. Albisser ${ }^{1}$ \\ ${ }^{1}$ The Hospital for Sick Children, ${ }^{2}$ The Toronto General Hospital, Toronto, Canada and \\ ${ }^{3}$ Osaka University Medical School, Osaka, Japan
}

Summary. The metabolic and hormonal consequences of long term intravenous insulin replacement were studied in 11 pancreatectomised dogs. Insulin was delivered into the portal circulation of six animals for 164-224 days and into the peripheral circulation of the remainder for 123-365 days. Infusion rates were initially adjusted to achieve normoglycaemia in the fasting $\left(0.37 \pm 0.01 \mathrm{mU} \mathrm{kg}^{-1} \mathrm{~min}^{-1}\right.$ portal; $0.45 \pm 0.03 \mathrm{mU} \mathrm{kg}^{-1} \mathrm{~min}^{-1}$ peripheral) and post-prandial states $\left(2.57 \pm 0.07 \mathrm{mU} \mathrm{kg}^{-1} \mathrm{~min}^{-1}\right.$ for $7^{1 / 2} \mathrm{~h}$ portal; $3.16 \pm 0.18 \mathrm{mU} \mathrm{kg}^{-1} \mathrm{~min}^{-1}$ for $7 \mathrm{~h}$ peripheral). Animals were fed their usual mixed diet and blood samples were drawn from indwelling catheters at regular intervals for $24 \mathrm{~h}$. A matched group of six normal dogs was similarly studied. Significantly less insulin was needed for glycaemic normalisation with portal $\left(1.05 \pm 0.03 \mathrm{U} \mathrm{kg}^{-1}\right.$ day $\left.^{-1}\right)$ compared with peripheral $\left(1.27 \pm 0.08 \mathrm{U} \mathrm{kg}^{-1} \mathrm{day}^{-1}\right)$ infusions, but post-prandial insulin levels were not normalised. Glucagon levels were normal and unaffected by the route of insulin infusion. Lactate and pyruvate responses were exaggerated post-prandially in the diabetic compared with the normal dogs. Fasting non-esterified fatty acid levels were suppressed with peripheral but normal with portal insulin infusion. There were only minor differences in the branched chain, essential and other non-essential amino acids except for alanine which was significantly above normal in the diabetic animals. Fasting levels of insulin, lactate, pyruvate and non-esterified fatty acids were normalised only with portal infusion while glucose, glucagon, 3-hydroxybutyrate and most amino acids were normalised regardless of the route of infusion. We conclude that the metabolic regulation achieved with portal insulin replacement is closer to normal than that achieved with peripheral infusion.
Key words: Metabolic response, glucose, insulin, glucagon, lactate, pyruvate, 3-hydroxybutyrate, alanine, non-esterified fatty acids, amino acids, portal, peripheral insulin infusion, diabetes, pancreatectomy

Long term (up to 2 years) blood glucose control in experimental diabetes is feasible. Using a portable hormone delivery device, glucose regulation was realised in pancreatectomised dogs for prolonged periods with insulin delivered either into the peripheral [1] or into the portal [2] circulations. To achieve close to normal glycaemic control three simple parameters relating to insulin requirements were programmed. These included a constant basal insulin infusion rate, a meal insulin rate and a time of duration of the meal rate. With the addition of two more parameters to define a second smaller meal insulin pulse, blood glucose control identical to normal was feasible [3].

Similar open-loop studies but of shorter duration (1-9 weeks) on insulin dependent diabetic patients have been reported with peripheral intravenous [4-7] and subcutaneous [8] insulin infusions. With peripherally infused insulin, such ideal blood glucose control is achieved only with a concomitant peripheral hyperinsulinaemia achieved either systemically [9] or locally [10] at the site of subcutaneous infusion. The metabolic effects of glucoregulation by these methods have been reported $[9,11,12]$. Since the portal (natural) route is not readily accessible for experimental insulin replacement in man, a series of animal experiments in pancreatectomised dogs was 
conducted to evaluate this route of insulin replacement as compared with peripheral IV insulin administration. The effects of short term insulin infusions into the portal and peripheral circulations of unanaesthetised normal dogs have been reported [13].

In the present studies the effects of long term insulin infusion into the portal and peripheral circulations of unrestrained diabetic dogs were explored. To this end, insulin infusion rates were adjusted to maintain fasting and post-prandial normoglycaemia and the resulting metabolic and hormonal responses were repeatedly measured.

\section{Materials and Methods}

\section{Animals}

Six healthy male beagle dogs weighing $14.0 \pm 0.8 \mathrm{~kg}$ were used as normal controls, and 11 similar animals were totally pancreatectomised. The peripherally infused diabetic group $(n=5)$ weighed $13.0 \pm 0.4 \mathrm{~kg}$ during the long term infusions which lasted 4-12 months, while the portally infused group ( $n=7$, one dog was sequentially in both groups), weighed $13.5 \pm 0.5 \mathrm{~kg}$ during the infusions which lasted 6-8 months. A fixed amount of food was given each morning. The results reported are only from dogs which ate all the food within $5 \mathrm{~min}$ of its presentation. The meal consisted of a mixture of two dog foods which included $360 \mathrm{~g}$ of soft meal (Meat Mix, Derby Pet Foods, Toronto, Ontario) and $260 \mathrm{~g}$ of dry chow (Master Premium Dinner, Maple Leaf Mills, Toronto, Ontario). The constant meal was approximately distributed as $33 \%$ protein, $30 \%$ fat, and $37 \%$ carbohydrate, the calculated total caloric content being about $1,300 \mathrm{kcal} /$ day. Besides the above described standard diet, 14 capsules of digestive enzymes (Cotazym, Organon, Montreal, Quebec) were mixed with the meals of pancreatectomised dogs to compensate for their surgically induced pancreatic exocrine insufficiency. The diabetic dogs had normal stools and maintained their weight. Several animals have been maintained on porcine insulin preparations for over three years without the development of anti-insulin antibodies insofar as this would be reflected as changes in immunoreactive non-specific insulin binding in the assay method used. All dogs were confined to their cages and were allowed access to water ad libitum.

In diabetic dogs, fasting plasma glucose concentrations were measured five days a week and based on these measurements the basal insulin infusion rates were initially adjusted individually to achieve normoglycaemia in the morning. Once stabilised, insulin requirements were constant for both routes but differed in amount as detailed below.

\section{Portable Insulin Delivery System}

The portable insulin delivery device consisted of a miniature peristaltic pump, a polyvinyl chloride insulin reservoir and a batterypower-pack which included a flow-rate controller, all the details of which have been published elsewhere $[14,15]$. The flow-rate controller [15] regulated by means of digital switch settings both the rate and the duration of a single square-wave pulse of insulin infusion as well as the rate of the chosen basal insulin infusion. The controller operated the pump every $90 \mathrm{~s}$. Thus, insulin was infused in pulses of constant rate (approximately $80 \mu \mathrm{l} / \mathrm{min}$ ) the duration of which varied according to the switch settings chosen for the basal or meal rates. Preprogrammed meal insulin infusion was initiated by activating a magnetic reed switch with an external permanent magnet within 5 min after the presentation of the meal. Following the termination of this meal insulin infusion the flowrate controller automatically returned to the pre-set basal rate. With these parameters the required basal rate was achieved with pulses that lasted $4-5 \mathrm{~s}$. This unphysiological method of insulin delivery conserved battery power because the motor ran intermittently. Reservoirs were emptied and refilled to capacity every three days with fresh porcine crystalline zinc insulin (Connaught Laboratories, Toronto, Ontario) diluted to a final concentration of $1240 \mathrm{U} / \mathrm{I}$ of insulin in $0.154 \mathrm{~mol} / 1$ saline adjusted to $\mathrm{pH} 7.4$. This frequent replacement of the insulin solution was necessitated because the hormone aggregated after 3-4 days. At this concentration of insulin, a negligible amount adhered to the reservoir and catheters.

\section{Catheterisation}

An indwelling silastic catheter was inserted into an external jugular vein of each normal and diabetic dog. Similarly a chronic indwelling catheter for insulin infusion was inserted directly into the portal vein of each diabetic dog at the time of pancreatectomy and into the inferior vena cava via the deep circumflex iliac vein, access to the latter being from a superficial branch of the same vein. The tip of the catheter was placed $3-4 \mathrm{~cm}$ distal to the porta hepatis so that insulin was delivered into the liver as uniformly as possible. All catheters were tunnelled beneath the skin to outlet sites on the back and entered the pockets of vest-like jackets which the dogs wore. Several dogs were able to remove the jackets and gained access to the catheters. Where this occurred repeatedly a loose collar was fitted. The techniques for continuous vascular access have been detailed previously [16].

\section{Blood Sampling}

Blood samples were taken via the indwelling sampling catheters in the diabetic dogs hourly starting at -1 and ending at $13 \mathrm{~h}$ with one final sample at $23 \mathrm{~h}$ for subsequent plasma glucose and insulin (IRI) determination. Samples were drawn at $-1,0,1,3,6,10,13$ and $23 \mathrm{~h}$ for the subsequent assay of glucagon (IRG), lactate, pyruvate, alanine, 3-hydroxybutyrate (3-OHB) and non-esterified fatty acid (NEFA) levels. Samples were drawn at $0,1,3,6$ and $10 \mathrm{~h}$ for the subsequent estimation of the following 14 amino acids: arginine, leucine, glycine, threonine, valine, lysine, serine, isoleucine, phenylalanine, histidine, ornithine, tyrosine, taurine and citrulline. In the normal dogs, similar blood sampling was done, but as previously detailed [17]. Total volume of blood drawn over $24 \mathrm{~h}$ was $60 \mathrm{ml}$. Blood withdrawn to clear dead space of catheters was reinjected.

Blood samples were drawn at the times specified above, and immediately transferred (a) into $1.5 \mathrm{ml}$ centrifuge tubes kept on ice and containing $0.03 \mathrm{ml}$ of heparin $1000 \mathrm{U} / \mathrm{ml}$, for glucose and IRI determinations; (b) into similar tubes containing aprotinin (Trasylol, 10,000 KIU/ml, FBA Pharmaceuticals, Ltd., Pte. Claire, Quebec) in a volume equal to $1 / 10$ that of the blood (with $24 \mathrm{mg}$ EDTA/ml double distilled water), for IRG and NEFA determinations; and, (c) into chilled tubes containing perchloric acid $(10 \mathrm{~g} / 100 \mathrm{ml})$ in a volume equal to that of the blood, for lactate, pyruvate and amino acid assays. Samples were centrifuged with minimal delay, the supernatants separated and frozen at $-20^{\circ} \mathrm{C}$ until subsequent assay. 


\section{Analytical Methods}

Glucose was determined using a glucose analyser (Beckman Instruments Inc., Fullerton, California). Plasma insulin (IRI) was assayed using an anti-pork insulin anti-serum (supplied by Dr. Peter Wright), purifjed pork insulin standard $\left(25.7 \mathrm{U} / \mathrm{mg},{ }^{125}[\right.$-labelled pork insulin, Novo Research Institute, Copenhagen, Denmark) and a dextran-coated charcoal separation of free from bound hormone. Plasma IRG was determined on unextracted plasma with anti-serum $30 \mathrm{~K}$ (obtained from Dr. R. H. Unger, Dallas, Texas), purified pork glucagon standard and ${ }^{125}$ I-labelled pork glucagon (Novo Research Institute, Copenhagen, Denmark), and the same dextran-coated charcoal separation technique. Lactate, pyruvate, and alanine were analysed by microfluorometric adaptations of standard enzymic methods, as previously detailed [18] employing an Aminco microphotometer (American Instrument Company, Division of Travenol Laboratories, Silver Springs, Maryland). Plasma NEFA levels were estimated by a radio-chemical microtechnique [19].

Whole blood amino acids were assayed in the perchloric acid supernatants on an amino acid analyser (Type $121 \mathrm{M}$, Beckman Instruments Inc., Palo Alto, California), using the manufacturer's protocol for elution of acidic, neutral and basic amino acids on a single column. Aspartate elutes with glutathione and therefore is not reported. Glutamine and glutamate are not accurately determined because of both storage and analytical conditions and similarly are not reported.

Standard statistical methods were employed using the unpaired Student ' $t$ ' test to compare groups. Repeated studies on the same animal were simply averaged to provide a single but better estimate of the response of that animal. For each group, the results were given as the mean of these estimates while the SEM was calculated on the basis of the number of different dogs (n).

\section{Protocols}

Meal responses in five diabetic dogs given peripheral insulin infusions: Glycaemia was controlled as previously detailed [1]. Each dog was studied repeatedly two to three times on widely separated occasions for a total of 13 trials $156 \pm 27$ days (range 63-274 days) after the start of the peripheral infusion which lasted $210 \pm$ 60 days (range 123-365 days). Near optimal glycaemic control was achieved repeatedly over the entire duration of these studies, notwithstanding technical difficulties with catheters, pumps and insulin aggregation.

Meal responses in seven diabetic dogs given portal insulin infusions: Glycaemia was stabilised as previously detailed [2]. Some dogs were repeatedly studied but on widely separated occasions for a total of 12 trials $61 \pm 14$ days (range 19-149 days) after the start of the portal infusion which lasted for $210 \pm 11$ days (range 164-224 days). One dog participated in both peripheral and portal infusion protocols.

Meal responses in normal dogs: The standardised diet was given to the six normal dogs at time 0 (approximately $0900 \mathrm{~h}$ ) and blood samples were drawn as defined previously [17]. Normal dogs were studied only once before pancreatectomy.

\section{Results}

Peripheral insulin requirements were $0.45 \pm 0.03$ $\mathrm{mU} \mathrm{kg}^{-1} \mathrm{~min}^{-1}$ in the fasting period and $3.16 \pm$ $0.18 \mathrm{mU} \mathrm{kg}^{-1} \mathrm{~min}^{-1}$ during the $7 \mathrm{~h}$ post-prandial infusion period. Portal insulin infusion rates were $0.37 \pm$
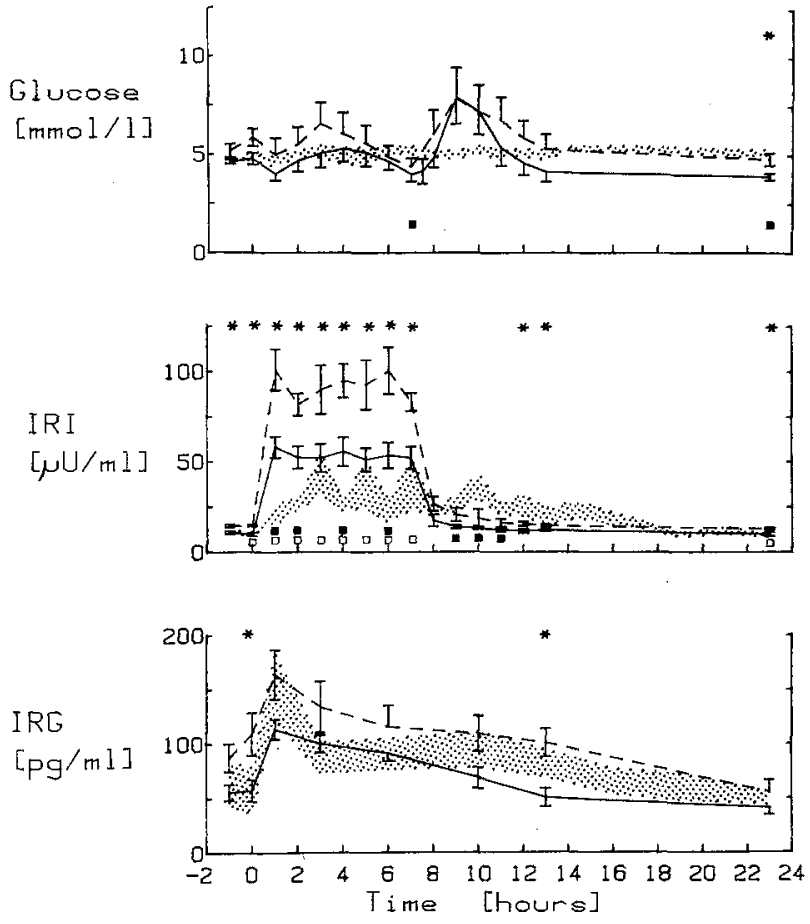

Fig. 1. Plasma glucose, insulin and glucagon levels in pancreatectomised dogs treated with portal or peripheral insulin infusions and in normal dogs.

Top: Plasma glucose in portally infused (straight line; $n=7$ ), peripherally infused (broken line; $n=5$ ), and normal dogs (stippled area; $n=6$ ), Centre: Plasma immunoreactive insulin (IRI) concentrations in portally infused ( $n=6$ ), peripherally infused ( $n$ $=5$ ), and normal dogs $(n=6)$; Bottom: Plasma immunoreactive insulin (IRG) concentrations in portally infused $(n=7)$, peripherally infused $(n=4)$, and normal dogs $(n=6)$

Meal eaten at time 0; Data expressed as mean \pm SEM; $\mathbf{\square =}$ normal versus portally infused dogs $(p<0.05) ; \square=$ normal versus peripherally infused dogs $(p<0.05) ;{ }^{*}=$ portally versus peripherally infused dogs $(p<0.05)$

$0.01 \mathrm{mU} \mathrm{kg}^{-1} \mathrm{~min}^{-1}$ in the fasting state and $2.57 \pm$ $0.07 \mathrm{mU} \mathrm{kg}^{-1} \mathrm{~min}^{-1}$ during the $71 / 2 \mathrm{~h}$ post-prandial period. A total of $1.05 \pm 0.03 \mathrm{U} \mathrm{kg}^{-1} \mathrm{day}^{-1}$ was delivered portally, significantly less $(p<0.05)$ than was required peripherally $\left(1.27 \pm 0.08 \mathrm{U} \mathrm{kg}^{-1} \mathrm{day}^{-1}\right)$ for glycaemic normalisation.

\section{Plasma Glucose (Fig. 1)}

The glycaemic response was generally similar to the normal controls in both diabetic groups showing no significant excursion in plasma glucose with meal ingestion. With peripheral insulin infusion glycaemia was slightly higher throughout, although the differences were significant only at $23 \mathrm{~h}$. A small excursion in glycaemia which was not seen in the normals occurred between $8-10 \mathrm{~h}$ in both diabetic groups following the termination of the meal insulin pulse. 

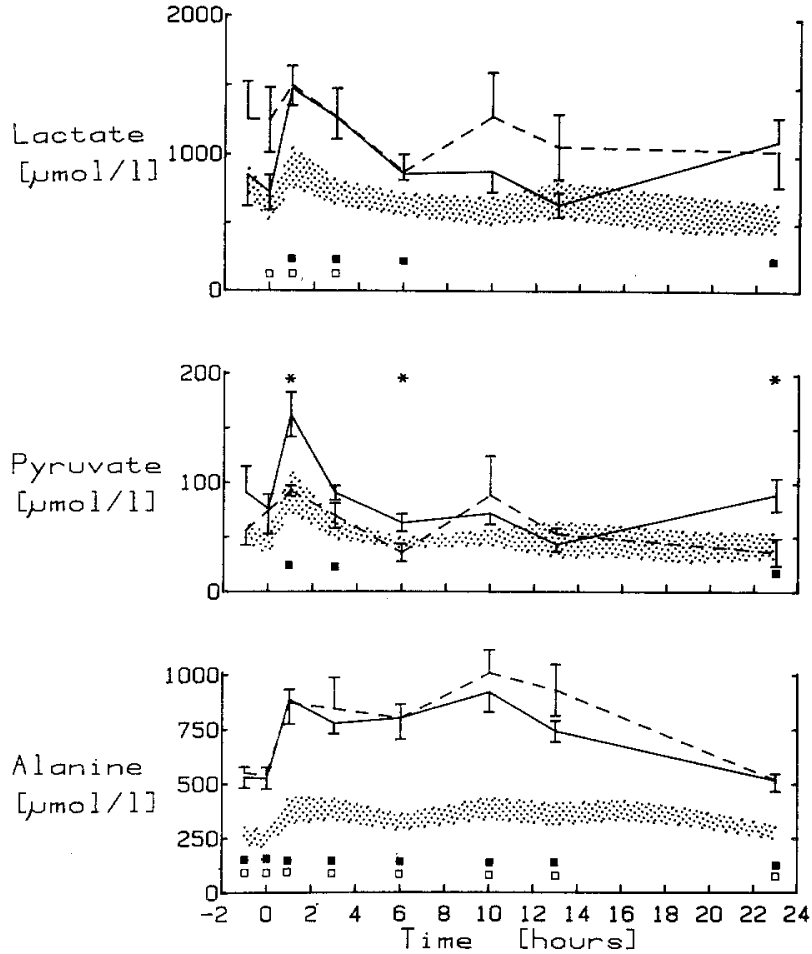

Fig. 2. Blood lactate, pyruvate and alanine levels in portally infused ( $n=6)$, peripherally infused $(n=4)$ and normal dogs ( $n$ $=6$ ). Symbols as Fig 1
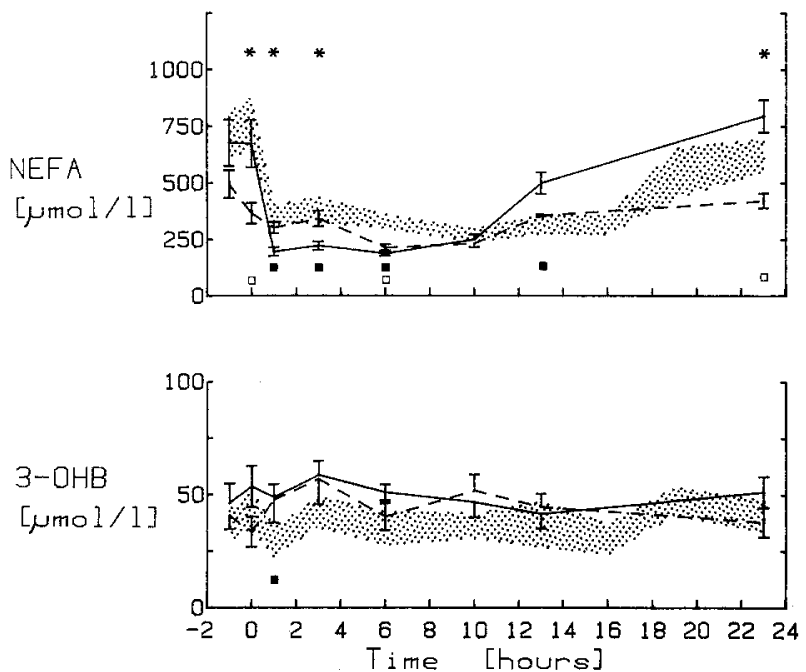

Fig. 3. Blood 3-hydroxybutryrate (3-OHB) and plasma nonesterified fatty acid (NEFA) concentrations in portally infused ( $n$ $=6)$, peripherally infused $(n=4)$ and normal dogs $(n=6)$. Symbols as Fig 1

\section{Plasma Insulin and Glucagon (Fig. 1)}

The plasma IRI concentrations were significantly different from normal in both diabetic groups. With peripheral infusion, insulin was slightly elevated in the post-absortive state $(0,23 \mathrm{~h})$ and was markedly elevated from $0-7 \mathrm{~h}$ post-prandially. With portal insulin infusion, IRI concentrations were normalised in the post-absorptive state and although still significantly elevated above normal post-prandially, the concentrations observed were only half those seen with the peripheral insulin infusions. Plasma IRI levels were significantly lower than normal for the portally infused group from 9-11 h.

Plasma IRG concentrations were normal or slightly higher than normal during peripheral insulin infusion but these differences were not significant. With peripheral insulin infusion, IRG was significantly above that seen with portal infusion at 0 and $13 \mathrm{~h}$.

\section{Blood Lactate, Pyruvate and Alanine (Fig. 2)}

Blood lactate and pyruvate levels tended to be in the normal fasting ranges but were elevated above normal post-prandially in the portally infused group. While lactate levels were elevated above normal in the peripherally infused group, pyruvate levels were in the normal range at all times. A significant twofold increase in alanine for both diabetic groups was present both in the post-absorptive and during the entire post-prandial periods.

\section{Plasma Non-esterfied Fatty Acids and Blood 3-Hydroxybuytyrate (Fig. 3)}

No significant differences in blood 3-hydroxybutyrate concentrations were present. The plasma NEFA levels showed changes very similar to the normals decreasing post-prandially. With peripheral insulin infusion, significantly lower NEFA levels were present at 0,6 , and $23 \mathrm{~h}$ while with portal insulin infusion NEFA was lower at 1,3 and $6 \mathrm{~h}$ and higher at $13 \mathrm{~h}$.

\section{Amino Acids (Table 1)}

The concentrations of seven amino acids in the postabsorptive state and their post-prandial levels are shown for peripheral and portal insulin infusion. The branched chain amino acids (leucine, isoleucine, and valine) showed profiles similar to those in normal dogs although several values were significantly higher. A similar response was seen for the essential amino acids, threonine and lysine. However, no significant differences in amino acids were apparent between peripheral or portal insulin infusions except at $3 \mathrm{~h}$ after the meal when valine levels were significantly elevated with the peripheral compared to portal infusions. The responses of the non-essential amino acids, arginine, glycine, serine, ornithine, 
Table 1. Fasting and post-prandial blood levels of selected amino acids in normal dogs and in pancreatectomised dogs with portal or peripheral insulin infusion

\begin{tabular}{|c|c|c|c|}
\hline \multirow[b]{2}{*}{$\begin{array}{l}\text { Time } \\
\text { (h) }\end{array}$} & \multirow{2}{*}{$\begin{array}{l}\text { Normal dogs } \\
(n=6) \\
(\mu \mathrm{mol} / \mathrm{l})\end{array}$} & \multicolumn{2}{|c|}{ Diabetic dogs } \\
\hline & & $\begin{array}{l}\text { Portal } \\
(n=5) \\
(\mu \mathrm{mol} / \mathrm{l})\end{array}$ & $\begin{array}{l}\text { Peripheral } \\
(n=5) \\
(\mu \mathrm{mol} / 1)\end{array}$ \\
\hline \multicolumn{4}{|c|}{ Leucine } \\
\hline 0 & $96 \pm 7$ & $59 \pm 8^{b}$ & $78 \pm 1$ \\
\hline 1 & $135 \pm 12$ & $183 \pm 32$ & $195 \pm 10^{b}$ \\
\hline 3 & $191 \pm 10$ & $203 \pm 16$ & $230 \pm 12^{a}$ \\
\hline 6 & $164 \pm 11$ & $225 \pm 8^{b}$ & $184 \pm 13$ \\
\hline 10 & $171 \pm 7$ & $165 \pm 16$ & $154 \pm 18$ \\
\hline 13 & - & $102 \pm 9$ & $118 \pm 10$ \\
\hline \multicolumn{4}{|c|}{ Isoleucine } \\
\hline 0 & $52 \pm 6$ & $41 \pm 3$ & $45 \pm 2$ \\
\hline 1 & $70 \pm 6$ & $85 \pm 9$ & $96 \pm 4^{b}$ \\
\hline 3 & $97 \pm 5$ & $100 \pm 7$ & $110 \pm 6$ \\
\hline 6 & $84 \pm 5$ & $109 \pm 4^{b}$ & $90 \pm 7$ \\
\hline 10 & $85 \pm 2$ & $81 \pm 7$ & $73 \pm 10$ \\
\hline 13 & - & $51 \pm 5$ & $61 \pm 5$ \\
\hline \multicolumn{4}{|c|}{ Valine } \\
\hline 0 & $111 \pm 12$ & $91 \pm 7$ & $106 \pm 5$ \\
\hline 1 & $174 \pm 21$ & $181 \pm 17$ & $228 \pm 15$ \\
\hline 3 & $259 \pm 15$ & $262 \pm 15^{\mathrm{d}}$ & $333 \pm 14^{b}$ \\
\hline 6 & $247 \pm 16$ & $337 \pm 20^{\mathrm{b}}$ & $294 \pm 30$ \\
\hline 10 & $245 \pm 6$ & $258 \pm 24$ & $229 \pm 26$ \\
\hline 13 & - & $159 \pm 15$ & $181 \pm 16$ \\
\hline \multicolumn{4}{|c|}{ Threonine } \\
\hline 0 & $248 \pm 41$ & $264 \pm 30$ & $304 \pm 37$ \\
\hline 1 & $267 \pm 38$ & $333 \pm 42$ & $403 \pm 56$ \\
\hline 3 & $296 \pm 32$ & $356 \pm 25$ & $448 \pm 60$ \\
\hline 6 & $301 \pm 30$ & $457 \pm 40^{\mathrm{a}}$ & $542 \pm 75^{a}$ \\
\hline 10 & $340 \pm 28$ & $556 \pm 37^{b}$ & $567 \pm 75^{\mathrm{a}}$ \\
\hline 13 & - & $477 \pm 43$ & $520 \pm 64$ \\
\hline \multicolumn{4}{|c|}{ Lysine } \\
\hline 0 & $243 \pm 28$ & $243 \pm 21$ & $258 \pm 21$ \\
\hline 1 & $289 \pm 40$ & $356 \pm 20$ & $378 \pm 26$ \\
\hline 3 & $282 \pm 25$ & $332 \pm 24$ & $360 \pm 31$ \\
\hline 6 & $259 \pm 18$ & $352 \pm 19^{b}$ & $368 \pm 23^{b}$ \\
\hline 10 & $283 \pm 23$ & $316 \pm 12$ & $320 \pm 29$ \\
\hline 13 & - & $235 \pm 16$ & $281 \pm 27$ \\
\hline \multicolumn{4}{|c|}{ Phenylalanine } \\
\hline 0 & $42 \pm 3$ & $32 \pm 1^{\text {bd }}$ & $39 \pm \quad 1$ \\
\hline 1 & $52 \pm 2$ & $61 \pm 6^{c}$ & $77 \pm 4^{b}$ \\
\hline 3 & $61 \pm 2$ & $63 \pm 6^{c}$ & $86 \pm 8^{a}$ \\
\hline 6 & $58 \pm 2$ & $70 \pm 6$ & $83 \pm 10$ \\
\hline 10 & $61 \pm 5$ & $59 \pm 5$ & $65 \pm 3$ \\
\hline 13 & - & $38 \pm 3^{d}$ & $54 \pm 3$ \\
\hline \multicolumn{4}{|c|}{ Histidine } \\
\hline 0 & $72 \pm 4$ & $67 \pm 1^{\mathrm{d}}$ & $80 \pm 3$ \\
\hline 1 & $77 \pm 6$ & $88 \pm 6$ & $104 \pm 7^{a}$ \\
\hline 3 & $95 \pm 6$ & $95 \pm 6$ & $111 \pm 10$ \\
\hline 6 & $91 \pm 6$ & $108 \pm 11$ & $106 \pm 5$ \\
\hline 10 & $102 \pm 5$ & $109 \pm 16$ & $119 \pm 7$ \\
\hline 13 & - & $92 \pm 4$ & $110 \pm 7$ \\
\hline
\end{tabular}

${ }^{\mathrm{a}} p<0.05, \quad{ }^{\mathrm{b}} p<0.01$ compared with control

c $p<0.05, \mathrm{~d} p<0.01$, peripheral compared with portal infusion in diabetic dogs.

Results are presented as mean \pm SEM. A meal was eaten at time 0 . For further details see Methods section tyrosine, citrulline, as well as taurine, were not remarkable (data not presented). However, the fasting levels of histidine and phenylalanine were higher in the peripherally infused compared with the portally infused group (Table 1).

\section{Discussion}

This study compared the metabolic and hormonal differences in diabetic dogs maintained in a normoglycaemic state by portal or peripheral insulin infusions. With peripheral insulin infusions hyperinsulinaemia was evident, mild in the post-absorptive and marked during the post-prandial states. However, the portal infusion of insulin resulted in a normalisation of post-absorptive insulinaemia and a significant reduction in the post-prandial hyperinsulinaemia. It is not at all clear why these animals required less insulin for glycaemic control when the hormone was infused portally, unless hepatic extraction of insulin was abnormally reduced. Perhaps the pulsatile nature of the insulin infusion waveform presented to the liver affects the extraction rate of insulin which is known to be approximately $50 \%$ of incoming insulin under steady state conditions [20].

Except for the recurrent task of changing insulin solutions in the reservoirs every three days the application of these systems to the animals was remarkably straightforward. None of the dogs became ill. Their weight was maintained and on the whole they ignored the apparatus on their backs. The long duration of each study was thus easy to accomplish. Hypoglycaemia was not encountered when appropriate infusion rates were established unless the animals failed to eat. The strategy of feeding first and then activating the meal insulin pulse ensured that hypoglycaemia was not produced. Fortunately, the good appetite of these animals resulted in the complete consumption of the meal within 5 min of its presentation. There appears to be no reason why such studies could not be continued indefinitely on this animal model. The methods for venous access both for blood sampling and insulin infusion [16] are robust and reliable. Ascending infections occurred infrequently and almost always resolved without intervention, as previously detailed [16].

Glucagon levels showed no major differences when insulin was given by either route. Despite improved insulin profiles the lactate, pyruvate and alanine responses were exaggerated post-prandially. It is particularly noteworthy that the twofold increase in alanine seen with peripheral insulin infusions was entirely unaltered when the portal route was used. The pathophysiology leading to the increased alanine 
levels in the diabetic dogs remains unclear. Unfortunately the data from this study do not indicate whether the elevated alanine levels reflected abnormal hepatic uptake or excessive peripheral production. We suspect that the pulsatile nature of the insulin infusion may account for the observed hyperalaninaemia with portal insulin replacement. Further studies with a continuous insulin infusion are underway to explore this interesting observation. Unexpectedly, the branched chain amino acids whose concentrations are known to be influenced by insulin levels in a reciprocal manner were in fact similar in both diabetic groups.

In the fasting state and from $10 \mathrm{~h}$ after the meal, the higher insulinaemia (approximately $+4 \mu \mathrm{U} / \mathrm{ml}$ ) with peripheral infusion as compared to portal infusion was probably responsible for the significantly lowered NEFA levels. When meal insulin was infused initially, the animals receiving portal insulin had lower NEFA levels but toward the end of the meal infusion similar NEFA levels were observed indicating that maximum inhibition of lipolysis was present in both groups. Similar effects on NEFA in insulin infused dogs have been reported by others [13].

The comparison between the metabolic profiles in these two groups of diabetic animals brings out certain other significant differences. Thus with peripheral infusions of insulin hyperinsulinaemia prevails in the presence of euglycaemia while NEFA levels are suppressed. The long term consequences of such hyperinsulinaemia with its subsequent effects on lipolysis, insulin receptors and fuel fluxes remain unknown, but may be important in the development of such diabetic complications as basement membrane changes and blood vessel disease.

These studies have demonstrated that glucagon from extrapancreatic sources responds normally to meal related secretagogues. Gut glucagon in this species is similar to pancreatic glucagon $[21,22]$ and the fasting levels correlate closely with the fasting levels of phenylalanine, alanine, and histidine in the diabetic groups. These amino acids are known stimulators of glucagon secretion in the intact dog $[23,24]$.

During the post-prandial period, the insulin excursion was some twofold greater in the peripherally infused group but this resulted in an approximately threefold smaller excursion in NEFA compared to portally infused dogs. These opposed differences reflect the overall suppression of lipolysis in the peripheral group. The post-prandial excursions in glucagon were not different and probably reflect the similar excursions in phenylalanine, alanine, and histidine observed.
These studies were conducted at various times at least 19 and up to 224 days after the start of insulin replacement by a given route. They therefore represent stable conditions which should accurately reflect the effects of the route used. Whether the subtle differences observed in the post-absorptive conditions or in the post-prandial excursions will have long term consequences remains to be established [25]. We conclude that the metabolic regulation achieved with portal insulin infusion is closer to normal than that achieved under similar circumstances with peripheral infusion in the totally insulin deficient dog. Such studies cannot be performed with currently available techniques in man. Though the dog shows the differences in post-prandial metabolic responses demonstrated by this and previous studies [17], notably the constant glycaemia and prolonged absorption of nutrients, it appears reasonable to assume that analogous differences between portal and peripheral insulin replacement will also occur in man. Thus, even the most sophisticated techniques of peripheral insulin delivery, whether intravenous or otherwise, will probably be associated with failure to normalise totally post-prandial fuel fluxes. This is most likely due to the necessity to perfuse the liver at portal venous insulin concentrations to achieve normal glycaemic responses. The resulting peripheral hyperinsulinaemia will have unavoidable consequences on other fuels as well as glucose. Whether these "new" abnormalities are less dangerous than the consequences of inadequate metabolic control by conventional insulin treatment remains to be established.

Acknowledgements. The Artificial Endocrine Pancreas Program is supported by grant MA5767 from the Medical Research Council of Canada and Negotiated Contract NO1-AM-9-2201 from the National Institutes of Health in Bethesda, Maryland. We wish to thank the Departments of Animal Care and Surgical Research at The Hospital for Sick Children for their cooperation and assistance in the studies presented here. The technical assistance of ChouNan Wei, Erlinda Gan, and Arthur Stein, is gratefully acknowledged. The manuscript was prepared by Debra Edwards.

\section{References}

1. Goriya Y, Bahoric A, Marliss EB, Zinman B, Albisser AM (1979) Glycemic regulation using a programmed insulin delivery device. III. Long-term studies on diabetic dogs. Diabetes 28: 558-564

2. Goriya Y, Bahoric A, Marliss EB, Ziman B, Albisser AM (1980) Blood glucose control and insulin clearance in unrestrained diabetic dogs portally infused with a portable insulin delivery system. Diabetologia 19: 452-457

3. Albisser AM, Goriya Y, Bahoric A, Marliss EB (1979) Glycemic normalization using a preprogrammed insulin delivery device in unrestrained diabetic dogs. In: Camerini Davalos RE, Hanoer B (eds) Early diagnosis of diabetes, Plenum Publishing Corp. pp 509-514 
4. Slama G, Hautecouverture M, Assan R, Tchobroutsky G (1974) One to five days of continuous intravenous insulin infusion on seven diabetic patients. Diabetes 23 : 732-738

5. Deckert T, Lorup B (1976) Regulation of brittle diabetics by a preplanned insulin infusion programme. Diabetologia 12: 573-579

6. Service FJ (1978) Normalization of plasma glucose of unstable diabetes: studies under ambulatory, fed conditions with pumped intravenous insulin. J Lab Clin Med 91: 480-489

7. Hanna AK, Minuk HL, Albisser AM, Marliss EB, Leibel BS, Zinman B (1980) A portable system for continuous intravenous insulin delivery: characteristics and results in diabetic patients. Diabetes Care 3: 1-8

8. Pickup JC, Keen H, Parsons JA, Alberti KGMM (1978) Continuous subcutaneous insulin infusion: an approach to achieving normoglycaemia. Br Med J 1: 204-207

9. Hanna AK, Zinman B, Nakhooda AF, Minuk HL, Stokes EF, Albisser AM, Leibel BS, Marliss EB (1980) Insulin, glucagon and amino acid levels during glycemic control by the artificial pancreas in diabetic man. Metabolism 29: 321-332

10. Champion MC, Shepherd GAA, Rodger NW, Dupre J (1980) Continuous subcutaneous infusion of insulin in the management of diabetes mellitus. Diabetes 29: 206-212

11. Zinman B, Stokes EF, Albisser AM, Hanna AK, Minuk HL, Stein AN, Leibel BS, Marliss EB (1979) The metabolic response to glycemic control by the artificial pancreas in diabetic man. Metabolism 28: 511-518

12. Albisser AM, Goriya Y, Bahoric A, Marliss EB, Zinman B (1979) Persistent hormonal and metabolic abnormalities inspite of glucose normalization: Long term studies with peripheral open-loop insulin delivery in diabetic dogs. In: Waldhaust WK (ed) International Congress Series No. 500, Diabetes, Proceedings of the 10th Congress of the International Diabetes Federation. Excerpta Medica pp 644-648

13. Stevenson RW, Parsons JA, Alberti KGMM (1978) Insulin infusion into the portal and peripheral circulations of unanaesthetised dogs. Clin Endocrinol 8: 335-347

14. Jackman WS, Lougheed W, Marliss EB, Zinman B, Albisser AM (1980) For insulin infusion: A miniature precision peristaltic pump and silicone rubber reservoir. Diabetes Care 3: 322-331.

15. Ferguson RT, Zinman B, Marliss EB, Albisser AM (1980) Electronic flow rate controller for a portable insulin infusion pump. Diabetes Care 3: 332--337
16. Bahoric A, Filler RM, Perlman K, Jackman WS, Albisser AM (1980) New devices and methods for long term vascular access for blood sampling and insulin infusion. Diabetes Care 3: 338-344

17. Goriya Y, Bahoric A, Marliss EB, Zinman B, Albisser AM (1981) Diurnal metabolic and hormonal responses to mixed meals in healthy dogs. Am J Physiol 240 (Endocrinol Metab 3): E54-E59

18. Girard JR, Cuendet GS, Marliss EB, Kervran A, Rieurort M, Assan R (1973) Fuels, hormones and liver metabolism at term and during the early postnatal period in the rat. J Clin Invest 52: 3190

19. Ho RJ (1970) Radiochemical assay of long-chain fatty acids using ${ }^{63} \mathrm{Ni}$ as tracer. Annal Biochem 36: 105-113

20. Kaden M, Harding P, Field JB (1973) Effect of intraduodenal glucose administration on hepatic extraction of insulin in the anesthetized dog. J Clin Invest 52: 2016-2028

21. Sasaki H, Rubalcava B, Baetens D, Blazquez E, Srikart CB, Orci L, Unger RH (1975) Identification of glucagon in the gastrointestinal tract. J Clin Invest 56: 135-145

22. Muller WA, Girardier L, Seydoux J, Berger M, Renold AE, Vranic M (1978) Extrapancreatic glucagon and glucagon-like immunoreactivity in depancreatized dogs. $\mathbf{J}$ Clin Invest 63: 124-132

23. Unger RH, Ohneda A, Aquilar-Parada E, Eisentrout AM (1969) The role of aminogenic glucagon secretion in blood glucose homeostasis. J Clin Invest 48: 810-822

24. Rocha DM, Faloona GR, Unger RH (1972) Glucagonstimulating activity of 20 amino acids in dogs. J Clin Invest 51: 2346-2351

25. Brown J, Mullen Y, Clark WR, Molnar G, Heininger D (1979) Importance of hepatic portal circulation for insulin action in streptozotocin-diabetic rats transplanted with fetal pancreases. J Clin Invest 64: 1688-1694

Received: 2 July 1980

and in revised form: 29 January 1981

Dr. A. M. Albisser

Biomedical Research

The Hospital for Sick Children

555 University Avenue

Toronto M5G IX8

Ontario, Canada 